\title{
12
}

\section{Desigualdades socioespaciais na Região Administrativa do Méier com base nos censos 1991, 2000 e 2010}

Elaine Carneiro Rosa* Julia Célia Mercedes Strauch ${ }^{* *}$

Cesar Ajara $^{*+*}$

\section{Resumo}

A Região Administrativa do Méier (RA XIII), localizada na zona norte da cidade do Rio de Janeiro, se destaca por apresentar importantes transformações socioeconômicas advindas da dinâmica territorial em curso na cidade. Essa região tem sido palco de expressivos investimentos públicos e privados movidos pela abertura de novos vetores espaciais em sua área de influência imediata. Tal processo tem acarretado, entre outros aspectos, uma acentuação da centralidade espacial no que toca à oferta de bens e serviços para a sua área de influência imediata. Destacam-se, ainda, os impactos dessa dinâmica sobre o mercado imobiliário. 0 presente trabalho utiliza uma metodologia pautada no emprego de indicadores socioeconômicos voltados à aferição das desigualdades socioespaciais existentes na RA do Méier, com base nos dados dos Censos 1991, 2000 e 2010, de modo a construir um índice sintético para cada decênio. Essa metodologia se apoia no emprego de correlação espacial e de mapas coropléticos para investigar o desenvolvimento socioeconômico na área de estudo. 0 emprego da correlação espacial possibilitou a identificação e análise de processos de segregação socioespacial em curso na região, uma vez que evidenciou distintos graus de similaridade e/ou diferença entre as unidades espaciais estudadas.

Palavras-Chave: Indicadores Espaciais; Correlação Espacial; e Segregação socioespacial.

"Engenheira Cartógrafa pela UERJ, especialista em Análise Ambiental e Gestão do Território pelo curso de pós graduação da Escola Nacional de Ciências Estatísticas(ENCE/BBGE)..

" Pesquisadora Titular da Escola Nacional de Ciências Estatísticas (ENCE/BGE) e Professora Adjunta da UERJ. Doutora em Engenharia de Sistemas e Computação pela UFRJ.

"*t. Geógrafo e Doutor em Geografia pela Universidade Federal do Rio de Janeiro. Pesquisador Titular aposentado da pós-graduação da Escola Nacional de Ciências Estatísticas (ENCE-IBGE). 


\section{Introdução}

0 Rio de Janeiro tem se tornado palco de investimentos públicos e privados visando 0 seu desenvolvimento econômico e social. Os megaeventos que acontecerão na cidade nos próximos anos, como a Copa do Mundo de 2014 e as Olimpíadas de 2016, são uma grande oportunidade para a realização de políticas públicas direcionadas à melhoria da qualidade de vida da população. Esses eventos têm o mérito de mobilizar a sociedade, pois trazem para 0 debate questões ligadas à dinâmica $\mathrm{e}$ ao modelo de desenvolvimento aplicado, isto é, todas as ações públicas deverão levar em conta aspectos sociais, econômicos e ambientais de interesse da sociedade. Assim sendo, adquire importância a participação da sociedade civil na discussão do modelo de cidade a ser almejado.

Em 2007, os jogos Pan-Americanos propiciaram o início de importantes investimentos em infraestrutura esportiva significativa para a cidade, principalmente na zona oeste, com a construção da Vila Panamericana, do parque aquático Maria Lenk, do HSBC Arena, entre outros. A zona norte da cidade também foi afetada com a construção do Estádio Olímpico João Havelange ("Engenhão") e com a reforma do ginásio do Maracanãzinho. Além disso, praticamente toda a cidade recebeu a idealização de projetos de modernização dos transportes e eixos viários.

Nesse contexto, a Região Administrativa do Méier (RA XIII), localizada na zona norte da cidade do Rio de Janeiro, se destaca por apresentar importantes transformações socioeconômicas advindas da dinâmica territorial em curso na cidade. Expressivos investimentos públicos e privados movidos pela abertura de novos vetores espaciais em sua área de influência imediata têm acarretado, entre outros aspectos, uma acentuação da centralidade espacial no que toca à oferta de bens e serviços para a sua área de influência imediata.

A zona norte é composta por 24 das 33 regiões administrativas da cidade do Rio de Janeiro. Dentre essas regiões, destaca-se a Região Administrativa do Méier (RA XIII), que sempre se despontou como importante centro de serviços, comércio e lazer, com expressiva centralidade urbana. Isto foi facilitado devido à implantação de importantes elementos de infraestrutura que permitiram a intensificação dos fluxos de pessoas e mercadorias nesta área, a exemplo da linha férrea e do metrô. Com isso, o mercado imobiliário ficou aquecido, havendo a construção de novas moradias para atender à grande demanda por imóveis na região. Como consequência disso, o setor de serviços e comércio ampliou suas atividades promovendo a implantação de shoppings centers, a exemplo do Norte Shopping, inaugurado em 1986, e de hipermercados, a exemplo do Walmart, inaugurado em 2000, visando suprir as necessidades dos novos moradores da RA e dos bairros vizinhos. 
Figura 1 Principais elementos estruturantes da RA do Méier

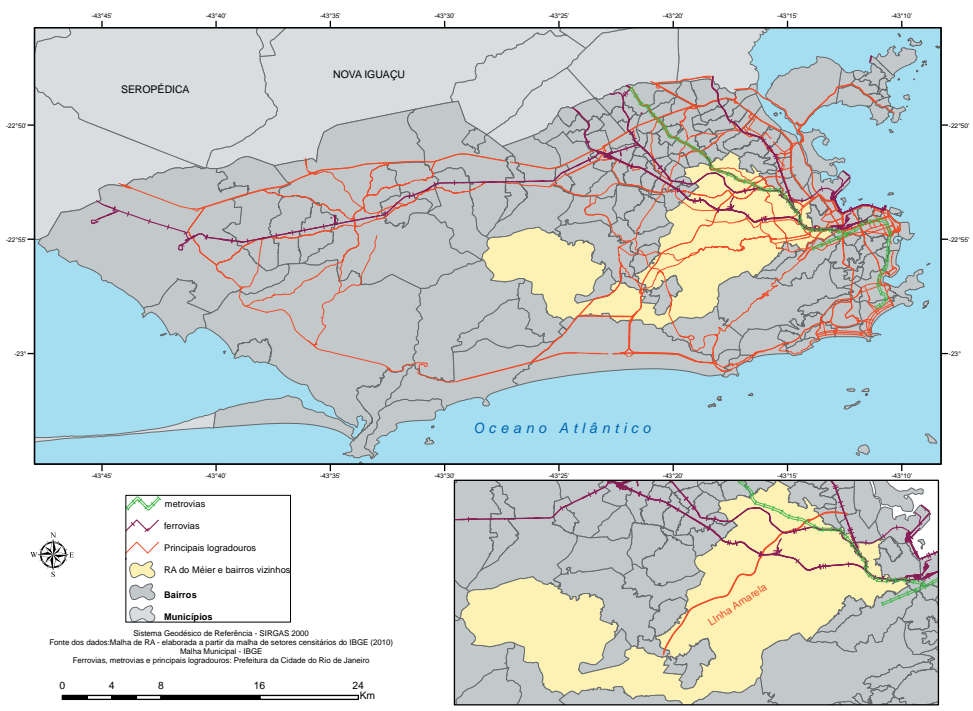

Na Figura 1, é possível notar a convergência de vários elementos de infraestrutura que garantem a conectividade da região com outras áreas da cidade, a exemplo da Linha Amarela, importante via expressa que atravessa toda a Região Administrativa fazendo a ligação com a Barra da Tijuca. Cabe salientar que tal eixo viário constitui uma das principais ligações a esse bairro. Assim sendo, a Região Administrativa do Méier vem consolidando seu status como grande polo de crescimento na cidade, estando atenta a todas as condicionantes para assegurar tal posição.

Desse modo, o presente trabalho visa identificar as principais transformações ocorridas na RA do Méier, com base nos dados dos Censos 1991, 2000 e 2010. Nesse sentido, a metodologia empregada encontra-se centrada na construção de um índice para cada ano censitário que possibilite comparar os bairros que compõem a RA de modo a identificar as desigualdades socioespaciais ali existentes. Essa metodologia faz uso das técnicas da estatística clássica, da análise espacial e em especial do índice de Moran para a análise da autocorrelação espacial dos índices.

\section{Área de estudo}

A Região Administrativa do Méier (RA XIII) é composta por 16 bairros, a saber: Abolição, Água Santa, Cachambi, Encantado, Engenho de Dentro, Engenho Novo, Ja- 
Figura 2 Região Administrativa do Méier

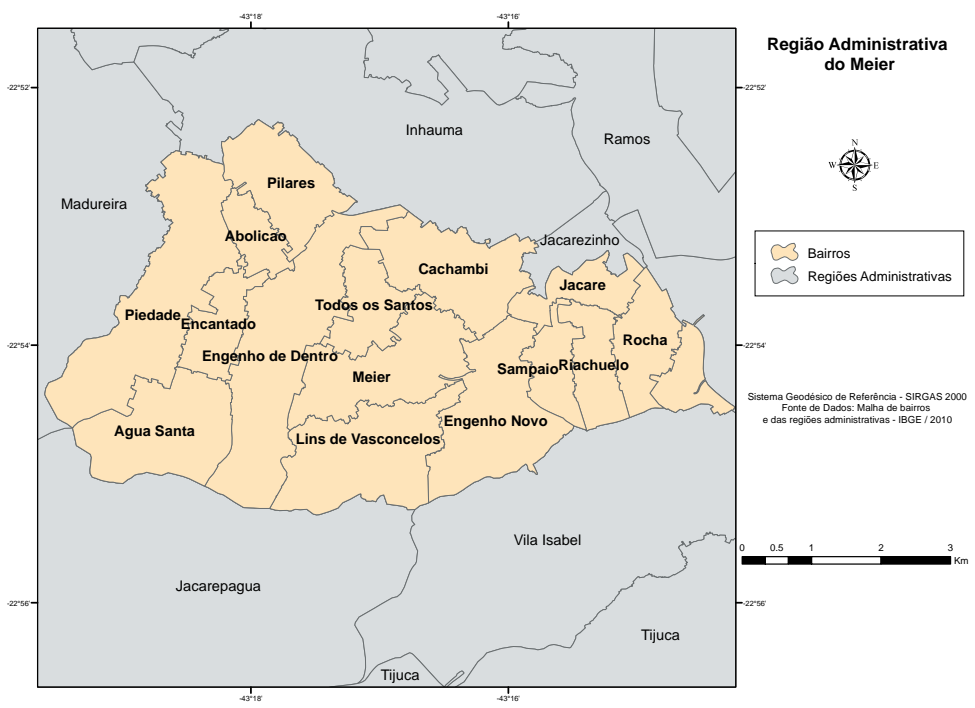

caré, Lins de Vasconcelos, Méier, Piedade, Pilares, Riachuelo, Rocha, Sampaio, São Francisco Xavier e Todos os Santos (Figura 2).

\section{Caracterização Socioeconômica}

Segundo o relatório sobre informações socioeconômicas, publicado pelo Serviço Brasileiro de Apoio às Micro e Pequenas Empresas, SEBRAE (2011), a Região Administrativa do Méier (RA XIII) tem uma população de 397782 habitantes, correspondentes a $6,29 \%$ do total da população da cidade do Rio de Janeiro, sendo a sua maioria pertencente à faixa etária de 50 ou mais anos, conforme se apresenta no Gráfico 1.

Os domicílios desta região têm em média, segundo os dados do Censo 2010, 2,9 moradores, uma das únicas RA da Área de Planejamento 3 que apresenta o índice próximo ao das regiões administrativas da zona sul da cidade do Rio de Janeiro.

A densidade demográfica da região, segundo dados do Sebrae (2011), é de 13 663,7 habitantes por km², sendo a sua distribuição por setores censitários, conforme se apresenta na Figura 3.

As moradias nesta região têm sido caracterizadas pelo aumento do número de apartamentos construídos, assinalando a tendência de verticalização das construções. Isto ocorre devido, principalmente, a redução de áreas passíveis de construção e ao aumento da procura por imóveis nesta região, ou seja, a demanda é grande 


\section{Gráfico 1 Faixa etária predominante na Região Administrativa do} Méier

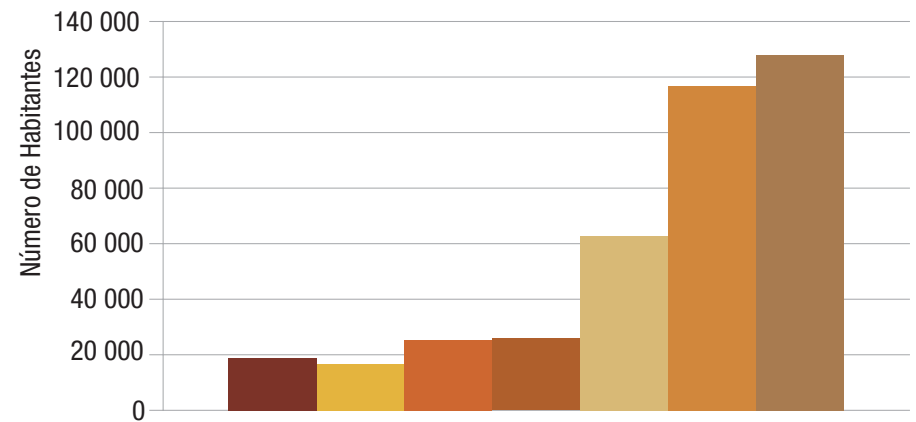

Faixa Etária

0-4 anos

5-9 anos

10-14 anos

$15-19$ anos

Fonte: Dados Sebrae (2011).

20-29 anos

30-49 anos

$50+$ anos

Figura 3 População na RA do Méier e seus arredores

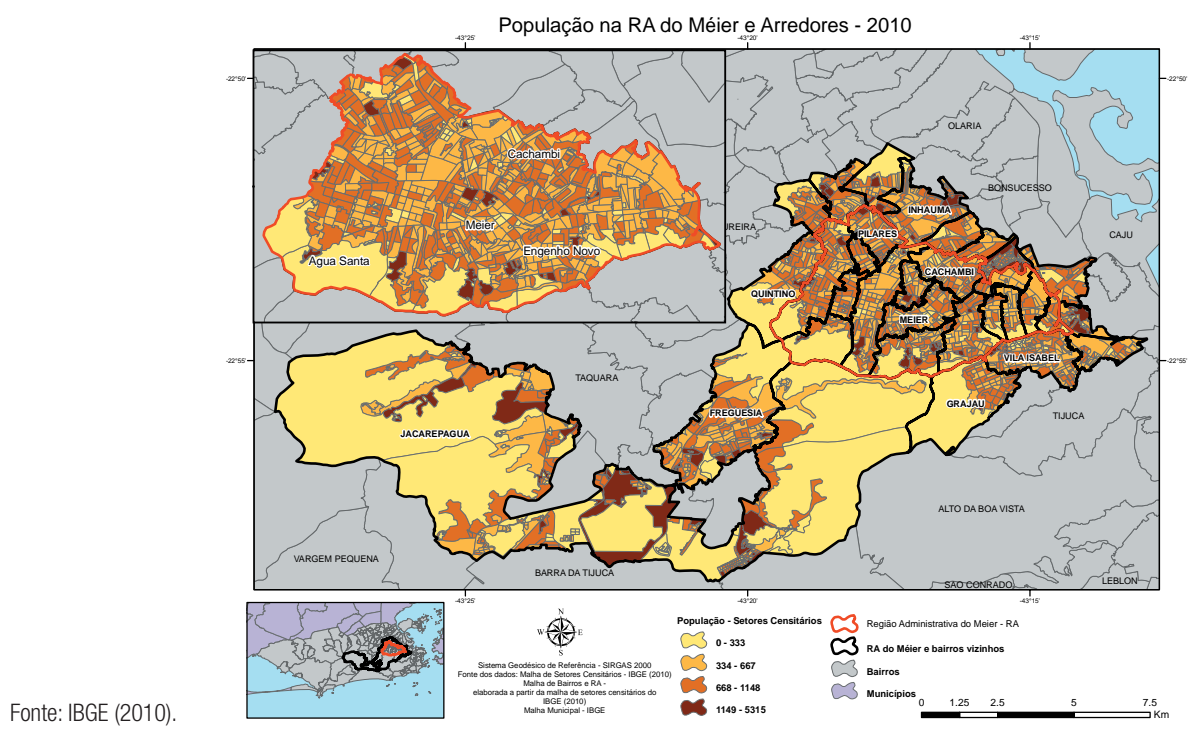


e a oferta por espaço, por muitas vezes, não atende à enorme procura. Sendo assim, visando otimizar as construções e atender ao maior número de interessados, a construção de edifícios constitui a melhor alternativa encontrada pelos planejadores urbanos e empreendedores imobiliários.

Analisando os dados do Censo 2010, observa-se que 0 eixo que liga as RAs de Irajá, Inhaúma e Méier corresponde à região com maiores tendências para a verticalização das construções da zona norte, juntamente com Tijuca e Vila Isabel, aproximando-se, inclusive, dos valores apresentados por regiões administrativas da zona sul e Barra da Tijuca. No que tange aos aspectos sociais da RA do Méier, o relatório sobre informações socioeconômicas, publicado pelo SEBRAE (2011), apresenta como método de avaliação dessas condições o Índice de Desenvolvimento Humano (IDH).

Segundo o PNUD (2010)1 , o IDH é uma medida resumida do progresso a longo prazo em três dimensões básicas do desenvolvimento humano: saúde, conhecimento e padrão de vida decente. Para o PNUD (2010), a variável medida na dimensão saúde é a expectativa de vida ao nascer, já a dimensão conhecimento se ocupa em medir os anos médios de estudo, caracterizado por discriminar o número médio de anos de educação recebido pelas pessoas que têm 25 anos ou mais, e os anos esperados de escolaridade, que representa o número de anos de escolaridade que uma criança na idade de entrar para a escola pode esperar receber. A dimensão padrão de vida decente utiliza a variável Renda Nacional Bruta (RNB) per capita, que representa, com mais precisão, os recursos que as pessoas dispõem para viver. Contudo, apesar de este índice ser amplamente utilizado, ressalta-se que ele é

Figura 4 Representação do Novo IDH

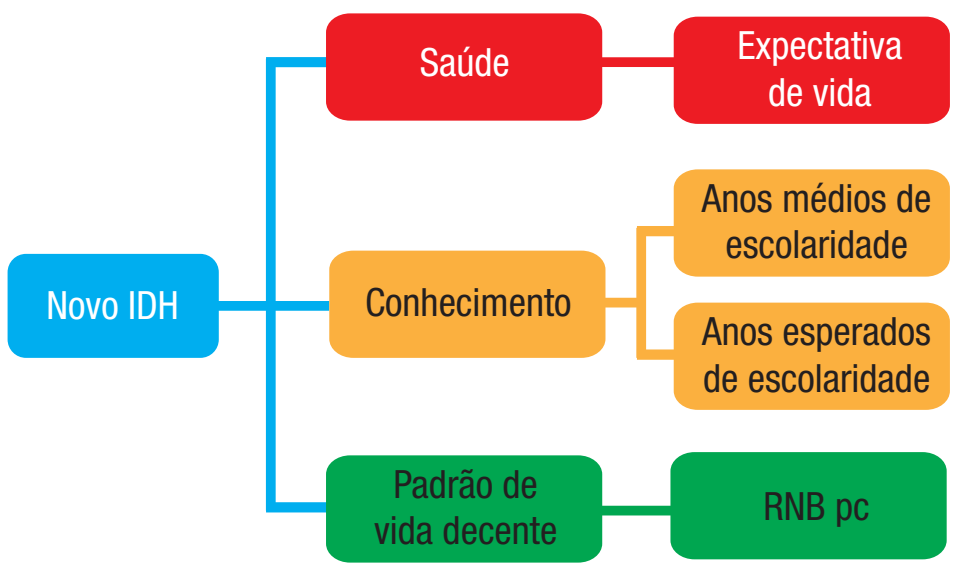

Fonte: PNUD (2012).

${ }^{1}$ http://www.pnud.org.br- acessado em 12/2012. 


\section{Tabela 1 Desenvolvimento Social na RA do Méier e no Município do Rio de Janeiro}

\begin{tabular}{lcc} 
Critérios & RA do Méier & Rio de Janeiro \\
\hline $\begin{array}{l}\text { Longevidade } \\
\text { (Esperança de vida ao nascer) }\end{array}$ & 71,5 anos & 70,2 anos \\
Média de Anos de Estudo & 7,7 anos & 6,8 anos
\end{tabular}

Fonte: Sebrae (2011).

apenas uma medida geral e sintética, e por isso, não abrange e nem esgota todos os aspectos do desenvolvimento.

0 IDH é um índice que varia de zero a 1, sendo dividido em três níveis de desenvolvimento humano, isto é: regiões com valores de até 0,5 de IDH são consideradas regiões de baixo desenvolvimento; regiões com IDH entre 0,5 e 0,8 são de médio desenvolvimento, e aquelas com IDH acima de 0,8 são ditas de alto desenvolvimento, ou seja, quanto mais próximo de 1, mais alto é o desenvolvimento humano. A Região Administrativa do Méier está classificada como de alto desenvolvimento humano, conforme critérios do IDH, por exemplo, os indicadores apresentados na Tabela 1.

A Região Administrativa do Méier apresenta, no item saúde, a longevidade considerada alta em relação ao Município do Rio de Janeiro, apresentando uma diferença de 1,3 ano. Em educação, segundo o mesmo relatório do SeBRAE (2011), a média de anos de estudo da Região Administrativa é de 7,7 anos, valor maior do que o observado para a cidade, que é de 6,8 anos. Além disso, ressalta-se o número de estudantes de ensino superior, que é de 19 150, e estudantes de mestrado ou doutorado, que representam $0,28 \%$ do total da população da região.

As atividades econômicas desenvolvidas na Região Administrativa do Méier têm seu forte na afirmação de microempresas, tendo em vista representarem cerca de $90 \%$ do número de estabelecimentos implantados no local (Tabela 2), de acordo com os dados da Relação Anual de Informações Sociais (RAIS), do Ministério do

Tabela 2 Número de estabelecimentos por porte 2009/2010 na RA do Méier.

\begin{tabular}{lcccc} 
& \multicolumn{2}{c}{$N^{0}$ de empresas } & \multicolumn{2}{c}{$\%$ de empresas } \\
\cline { 2 - 5 } Porte & 2009 & 2010 & 2009 & 2010 \\
\hline Micro & 12181 & 12433 & 89,21 & 89,11 \\
Pequena & 1249 & 1285 & 9,15 & 9,21 \\
\hline Média & 128 & 132 & 0,94 & 0,95 \\
Grande & 96 & 103 & 0,70 & 0,74 \\
Total & 13654 & 13953 & 100,00 & 100,00
\end{tabular}

Fonte: SebraE (2011). 
Trabalho e Emprego. Esta pesquisa é realizada através de um questionário anual, preenchido obrigatoriamente por todas as firmas registradas no País.

Os estabelecimentos implantados são divididos nos setores de: serviços, indústria, comércio e agropecuária, sendo o destaque, nesta região, o setor de serviços. Neste setor, a Região Administrativa do Méier apresenta, segundo o relatório do SEBRAE (2011), 1233 condomínios prediais, importância declarada, em decorrência da crescente verticalização das construções na região, 635 estabelecimentos de serviço de alimentação e 370 estabelecimentos de tratamento de beleza. Além do setor de serviços, o setor de comércio também se desponta como um dos fortes da região, principalmente no bairro do Méier, tendo em vista, ser um bairro central dado o seu caráter atrativo, justamente por oferecer serviços e ser polo empregatício. Neste setor, 0 destaque é 0 comércio varejista de artigos de vestuário e acessórios com 425 estabelecimentos, fato explicado também pela presença de importantes shoppings centers na região e seus arredores.

As atividades econômicas são fomentadas pelo potencial de consumo de uma dada região. No caso da Região Administrativa do Méier, segundo o mesmo relatório do SeBRAE, o consumo per capita anual urbano da Região Administrativa do Méier é

\section{Gráfico 2 Classes Econômicas da Região Administrativa do Méier}

\begin{tabular}{|cc|}
\hline $\begin{array}{c}\text { Classe } \\
\text { econômica }\end{array}$ & $\begin{array}{c}\text { Número de } \\
\text { domicílios } \\
\text { urbanos }\end{array}$ \\
\hline A1 & 1564 \\
A2 & 9479 \\
B1 & 25070 \\
B2 & 39676 \\
C1 & 34112 \\
C2 & 17596 \\
D & 11180 \\
E & 521 \\
Total & 139218 \\
\hline
\end{tabular}

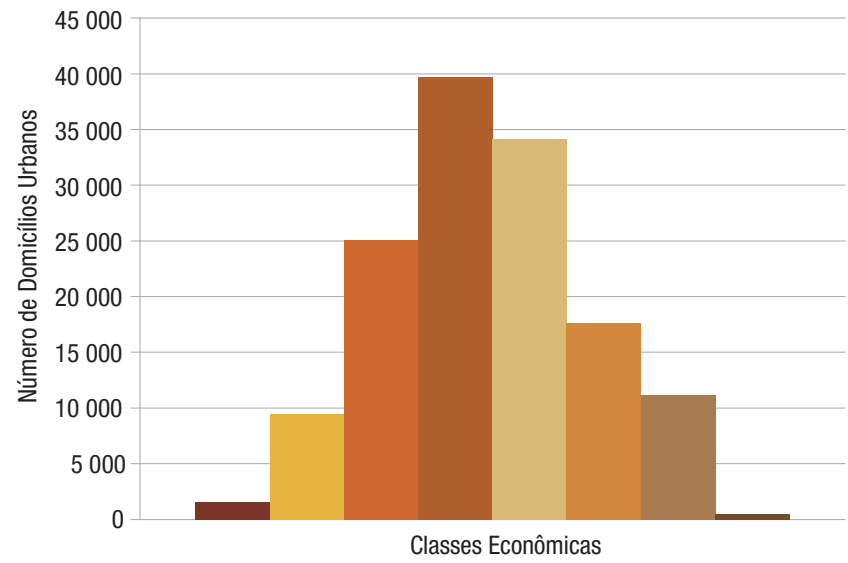

\begin{tabular}{ll|l|l|l|l|l|l|l}
$\mathrm{A} 1$ & $\mathrm{~A} 2$ & $\mathrm{~B} 1$ & $\mathrm{~B} 2$ & $\mathrm{C} 1$ & $\mathrm{C} 2$ & $\mathrm{D}$ & $\mathrm{E}$
\end{tabular} 
de $R \$ 23$ 495,78. Este consumo é calculado dividindo-se o montante de consumo da população, respectivamente, pelo número de pessoas dessa mesma população da região. Isto é fundamental para auxiliar no planejamento empresarial, já que com isto é possível identificar a capacidade de compra do público pretendido, a diversificação de produtos a serem ofertados, as condições comerciais específicas para este público e outros aspectos importantes para um bom planejamento de marketing.

Para avaliar as condições reais de compra da população, é importante que se observe as despesas da população local, nas categorias de consumo estabelecidas na Pesquisa de Orçamento Familiar (POF) realizada pelo IBGE, levando em consideração a classificação dos domicílios segundo o critério de Classificação Econômica Brasil. Isto possibilita que se verifique as classes econômicas da população caracterizada por ser o público alvo das empresas. A classe econômica B2, caracterizada pela renda média mensal de $R \$ 2300,00$, é a mais representativa na Região Administrativa do Méier. Esta classe social, segundo dados do mesmo relatório, tem 0 seu maior gasto com a manutenção do lar seguido de despesas como gastos com cabeleireiros, manicures, sapateiros, entre outros, e da alimentação, já o menor gasto está na compra de vestuário. Estes resultados permitem aprofundar o conhecimento sobre as diferenças do padrão de consumo entre as diversas classes de renda, porém as observações destacadas não esgotam as possibilidades de análise dos dados que mostram o comportamento do consumo local.

\section{Vetores recentes da dinâmica do território na RA do Méier}

As transformações socioeconômicas ocorridas na Região Administrativa do Méier, no período 1991/2010, associam-se, sobremodo, à implementação de vetores estruturantes da dinâmica territorial em curso na região e em sua área de influência imediata. Assume destaque a abertura de vias expressas que contribuíram para acentuar a centralidade espacial da região, com impactos significativos no mercado imobiliário.

Nesse contexto, assume especial importância a abertura da Linha Amarela. Essa via expressa foi construída com 0 objetivo de realizar a adequação viária da Baixada de Jacarepaguá, visando o seu crescimento e uma melhor integração com 0 restante da cidade, a exemplo da sua antecessora, a autoestrada Lagoa-Barra. Segundo Kleiman (2010), a Linha Amarela foi concebida no "Plano Doxiadis" de 1967, sendo este caracterizado por propor 0 desenvolvimento urbano de longa duração para 0 Estado, porém sua construção se iniciou efetivamente no final de 1994 e sua inauguração se deu 30 anos depois, em 1997. A via expressa contribui para 
as mudanças na mobilidade, e para alavancar a ocupação imobiliária residencial e comercial da Barra da Tijuca e as regiões adjacentes, e na remodelação dos bairros suburbanos. Em termos funcionais, esta via materializa o "eixo transversal" proposto no Plano Lucio Costa, visando a acessibilidade das camadas menos favorecidas, principalmente os subúrbios, a todos os equipamentos de consumo, lazer e serviços que a Barra da Tijuca, propicia. Nos Subúrbios, a Linha Amarela passa "por cima" de outras vias, cortando e separando a estrutura urbanística, contribuindo para a descontinuidade da paisagem. Para Kleiman (2010), "a via expressa com seu território fechado, viadutos, acessos em rampa, corta e substitui a estrutura de ruas sinuosas, estreitas, com forte porosidade, e separa parte, divide bairros suburbanos ao meio. Onde antes se percorria a pé todo um bairro, atualmente a circulação só é possível de veículo automotor." Todavia, na região da Barra da Tiju$\mathrm{ca}$, a via é parte integrante da paisagem urbana, concebida por Lucio Costa, onde a cidade adapta-se ao automóvel.

A abertura da Linha Amarela tem possibilitado o lançamento de muitos empreendimentos imobiliários às suas margens em áreas vizinhas levando a que, em 2006 e 2007, segundo a Associação de Dirigentes de Empresas do Mercado Imobiliário (ADEMI, 2012), os subúrbios já participavam com importante percentual de lançamentos imobiliários na capital, através de condomínios de prédios residenciais com equipamentos de lazer (piscinas, clubes, etc.) em locais próximos a grandes centros comerciais, muitos criados no mesmo período.

As transformações que ocorreram nesta região são notórias, visto compreender uma área onde inexistia comércio de grande porte. Sendo assim, a abertura da via expressa ativa a capacidade de atração de grandes centros comerciais, principalmente, em vastos terrenos industriais desativados, a exemplo do Norte Shopping e do Shopping Nova América. 0 Norte Shopping conta com hipermercado, centro médico, salas de escritórios, cinemas, teatros, universidade, entre outros serviços, além das estruturas comerciais criadas ao seu redor como: o Walmart, Leroy Merlin e hipermercado Extra, inaugurados na década de 2000. 0 Shopping Nova América, inaugurado na década de 1990 nas instalações de uma antiga fábrica têxtil de mesmo nome (edificação protegida pelo patrimônio histórico do Rio de Janeiro) também apresenta concepção multiuso com lojas, áreas de lazer com bares, cinemas e também uma universidade. Este shopping conta hoje com um projeto de expansão de suas lojas, construção de hotel, de centro de convenções e ampliação do estacionamento. Tal fato propiciará um aumento na oferta de atrações estimulando o aumento de visitações ao local, uma vez que este shopping apresenta ligação direta com uma estação de metrô (Del Castilho), 0 que facilita 0 acesso de visitantes da baixada e da zona sul. 


\section{Metodologia}

Entende-se que a geração de informações, a partir do mapeamento e análise de indicadores seja fundamental para a realização de um diagnóstico socioeconômico da região estudada. Desse modo, o presente trabalho utiliza uma metodologia pautada no emprego de indicadores socioeconômicos voltados à aferição das transformações ocorridas na RA do Méier, no período de 1991/2010, construindo um índice sintético para cada decênio. Essa metodologia se apoia no emprego de correlação espacial, usando como critério de vizinhança a conectividade dos bairros e de mapas coropléticos para investigar o desenvolvimento socioeconômico na área de estudo. Devido ao critério de vizinhança utilizado, além dos 16 bairros da RA XIII, foram considerados na área de estudo 15 bairros de outras RAs que possuem limite comuns aos bairros, perfazendo um total de 31 bairros como área de estudo.

\section{Materiais}

A base tabular dos dados censitários foi obtida a partir de pesquisas no portal da prefeitura da cidade do Rio de Janeiro ${ }^{2}$ e no site do $\mathrm{IBGE}^{3}$, utilizando 0 critério de serem relativas aos bairros da RA do Méier e seus vizinhos. A edição dessa base foi realizada no software Excel 2010, a partir dos cálculos das proporções dos indicadores e da padronização dos dados, bem como, posteriormente, a realização do cálculo da matriz de correlação.

A base cartográfica vetorial referente à malha de setores censitários de 1991, 2000 e 2010 foi cedida pelo IBGE, estando todas referenciadas no sistema de coordenadas geodésico e na escala de 1:250 000. As bases de 1991 e 2000 foram produzidas no sistema geodésico de referência SAD-69 e a malha setorial de 2010 no SIRGAS 2000. Sendo assim, visando compatibilizar todos os sistemas para o oficial do País que é o SIRGAS 2000, fez-se as transformações necessárias no ambiente ArcGis $10 \mathrm{com}$ base nos parâmetros de transformação indicados pelo IBGE. As demais bases cartográficas a citar: a malha municipal, de áreas de planejamento, de regiões administrativas e de bairros foram produzidas a partir de procedimentos de agregação e generalização espacial realizado em um ambiente de Sistema de Informações Geográficas (SIG).

${ }^{2}$ http://www.armazemdedados.rio.rj.gov.br/

${ }^{3} \mathrm{http}: / /$ www.ibge.gov.br/home/ 
Os mapas coropléticos e a análise espacial foram realizados no ambiente ArcGis 10, sob licença cedida pela ENCE (Escola Nacional de Ciências Estatísticas), e 0 cálculo do índice de Moran e da matriz de proximidade foi realizado no Terraview 4.1, complementado pela construção do diagrama de espalhamento deste índice, no aplicativo livre Geoda 1.2.

\section{Etapas}

0 trabalho foi desenvolvido observando as seguintes etapas:

1. Seleção dos indicadores para os Censos 1991, 2000 e 2010;

2. Padronização dos indicadores;

3. Análise exploratória dos indicadores;

4. Construção da base cartográfica para os anos: 1991, 2000 e 2010;

5. Construção dos índices para cada ano de pesquisa censitária;

6. Análise de correlação espacial;

7. Construção dos mapas temáticos; e

8. Interpretação dos mapas gerados.

\section{Indicadores selecionados}

0 Quadro 1 apresenta todas as variáveis utilizadas na pesquisa. Para a sua melhor compreensão, foi criado um atributo Gráfico que classifica os indicadores de acordo com a legenda abaixo.

- $\quad$ - Indicadores cujo crescimento resulta em aspectos positivos; e

- $\because$ Indicadores cujo crescimento resulta em aspectos negativos.

\section{Padronização dos indicadores}

Tendo os indicadores selecionados, fez-se a organização dos registros de cada bairro pertencente a RA do Méier e seus vizinhos, calculando, em seguida, todos os valores dos indicadores em proporção. 0 próximo passo consistiu em efetuar a padronização dos índices de 0 a 1 . Esta padronização permite uma melhor verificação do comportamento dos dados, pois facilita a visualização do ranking do indicador, isto 
Quadro 1 Indicadores selecionados

\begin{tabular}{|c|c|c|}
\hline Indicador & Descrição & Aspecto \\
\hline Mord & Média de moradores por domicílio particular permanente por bairro. & $\ddot{\theta}$ \\
\hline Propdep & $\begin{array}{l}\text { Proporção de pessoas dependentes ( } 0 \text { a } 14 \text { anos e } 65 \text { a } 100 \text { anos) } \\
\text { por domicílio por bairro. }\end{array}$ & ஜே \\
\hline Proquipro & Proporção de domicílios particulares permanentes próprios por bairro. & $(\ddot{)}$ \\
\hline Prodomalug & Proporção de domicílios particulares permanentes alugados por bairro. & $(\bullet)$ \\
\hline Popfav & Proporção da população residente em favela por bairro. & $\ddot{\sigma}$ \\
\hline Propcasa & Proporção de domicílios tipo casa por bairro. & $(\bullet)$ \\
\hline Propapto & Proporção de domicílios tipo apartamento por bairro. & $(\bullet)$ \\
\hline Proaguared & $\begin{array}{l}\text { Proporção de domicílios ligados a rede pública urbana de abastecimento } \\
\text { de água da rede geral por bairro. }\end{array}$ & (8) \\
\hline Proesgred & $\begin{array}{l}\text { Proporção de domicílios particulares permanentes com banheiro ou sanitário } \\
\text { e esgotamento sanitário via rede geral de esgoto ou pluvial por bairro. }\end{array}$ & \\
\hline Prolix & $\begin{array}{l}\text { Proporção de domicílios particulares permanentes com lixo coletado por } \\
\text { bairro. }\end{array}$ & 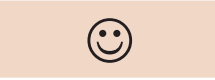 \\
\hline Superior & $\begin{array}{l}\text { Proporção de responsáveis por domicílio que tem como última série } \\
\text { frequentada o curso superior por bairro. }\end{array}$ & $(-)$ \\
\hline Popanalf & Proporção de pessoas com 5 anos ou mais de idade analfabetas por bairro. & $\ddot{\theta}$ \\
\hline Até $5 \mathrm{sm} /$ & $\begin{array}{l}\text { - Proporção de responsáveis por domicílios particulares permanentes com } \\
\text { rendimento nominal mensal de até } 5 \text { salários mínimos por bairro. }\end{array}$ & Até 5 salários. \\
\hline 5 a $10 \mathrm{sm} /$ & $\begin{array}{l}\text { - Proporção de responsáveis por domicílios particulares permanentes com } \\
\text { rendimento nominal mensal de } 5 \text { até10 salários mínimos por bairro. }\end{array}$ & De 5 a 10 salários. \\
\hline $10 \mathrm{sm}$ & $\begin{array}{l}\text { - Proporção de responsáveis por domicílios particulares permanentes com } \\
\text { rendimento nominal mensal de mais de } 10 \text { salários mínimos por bairro. }\end{array}$ & Mais de 10 salários. \\
\hline
\end{tabular}

é, com a padronização se torna mais direta a análise da qualidade dos dados, verificando se os resultados dos mesmos é bom ou ruim. Para estabelecer uma escala de 0 a 1 para todos os indicadores utilizados foram utilizadas as seguintes equações:

$$
I i=\frac{E i-E \min }{E \max -E \min } \quad \text { Equação } 3 \quad I i=\frac{E i-E \max }{E \min -E \max } \quad \text { Equação } 4
$$


A seleção da equação a ser aplicada a cada indicador levou em consideração a análise apresentada no Quadro 1 que qualifica 0 indicador de acordo com seu tipo de crescimento, resultando em aspectos negativos ou positivos. Assim, a Equação 3 é aplicada quando 0 valor alto significa um aspecto positivo, já a Equação 4 é utilizada quando 0 crescimento do indicador significa um aspecto negativo.

Desta forma, cada indicador foi padronizado, atendendo aos critérios estabelecidos nas equações de padronização, apresentando um intervalo de 0 a 1 entre os bairros, ou seja, o bairro que apresentasse 0 valor do indicador mais próximo de 1 tem 0 melhor resultado em comparação com os demais. Ressalta-se que não necessariamente este valor é o melhor do Município, mas com certeza ele é o meIhor dentre a amostra selecionada, já que se levou em consideração os máximos e mínimos dos indicadores de cada bairro da RA XIII, objeto de estudo desta pesquisa.

\section{Análise exploratória}

Dentre os indicadores estudados, não houve outliers e missing data. A elaboração das matrizes de correlação para cada ano de pesquisa censitária objetivou refinar a analise exploratória. A Tabela 3 apresenta a matriz de correlação apenas para 0 ano de 2010. Apesar de alguns indicadores apresentarem uma correlação maior que $\pm 0,7,0$ único indicador excluído em função desta análise foi proporção de domicílios em favela, visto ser redundante ao se comparar a proporção de moradores em favela. Os demais indicadores foram considerados.

\section{Construção da base de dados}

Para efetuar a análise espacial, é necessário construir uma base de dados em ambiente de sistema de informações geográficas de modo a atribuir aos dados tabulares a sua relação com 0 espaço.

Tendo em vista que os limites dos bairros foram mudando com o passar dos anos, nesta etapa levou-se em conta as peculiaridades de traçado, tomando-se 0 cuidado de cada tabela estar associada à base cartográfica dos bairros correspondentes.

A seguir, efetuou-se uma união entre as tabelas com os dados das pesquisas censitárias e a base cartográfica dos bairros constituintes da RA do Méier e seus vizinhos, tendo como atributo de ligação o geocódigo proposto pelo IBGE. Isto possibilitou associar dados dos Censos de 1991, 2000 e 2010 aos devidos recortes espaciais. 
Tabela 3 Matriz de correlação das variáveis selecionadas para 2010

\begin{tabular}{|c|c|c|c|c|c|c|c|c|c|c|c|c|c|c|c|}
\hline & 1 & 2 & 3 & 4 & 5 & 6 & 7 & 8 & 9 & 10 & 11 & 12 & 13 & 14 & 15 \\
\hline \multicolumn{2}{|r|}{ I_mord } & _propdep & I_proquipr & I_prodomal & I_domfav & I_popfav & I_propcasa & I_proprapt & I_proagua & I_proesgre & I_prolix & _ppopanalf & 1_5a10sm & I_10sm & Late $5 \mathrm{sm}$ \\
\hline 1 & 1,00 & 0,37 & $-0,54$ & 0,23 & 0,71 & 0,77 & $-0,80$ & 0,30 & 0,13 & 0,40 & 0,41 & 0,75 & 0,77 & 0,68 & $-0,69$ \\
\hline 2 & 0,37 & 1,00 & $-0,58$ & 0,26 & 0,19 & 0,21 & $-0,55$ & 0,24 & 0,04 & $-0,19$ & 0,09 & 0,33 & 0,38 & 0,30 & $-0,28$ \\
\hline 3 & $-0,54$ & $-0,58$ & 1,00 & $-0,77$ & $-0,21$ & $-0,30$ & 0,48 & $-0,34$ & $-0,00$ & 0,00 & $-0,19$ & $-0,33$ & $-0,32$ & $-0,23$ & 0,24 \\
\hline 4 & 0,23 & 0,26 & $-0,77$ & 1,00 & $-0,20$ & $-0,11$ & $-0,02$ & 0,07 & $-0,02$ & 0,00 & $-0,15$ & 0,02 & $-0,06$ & $-0,09$ & 0,10 \\
\hline 5 & 0,71 & 0,19 & $-0,21$ & $-0,20$ & 1,00 & 0,99 & $-0,65$ & 0,29 & 0,18 & 0,38 & 0,75 & 0,88 & 0,49 & 0,37 & $-0,42$ \\
\hline 6 & 0,77 & 0,21 & $-0,30$ & $-0,11$ & 0,99 & 1,00 & $-0,68$ & 0,34 & 0,19 & 0,35 & 0,73 & 0,8 & 0,54 & 0,43 & $-0,47$ \\
\hline 7 & $-0,81$ & $-0,55$ & 0,48 & $-0,024$ & $-0,65$ & $-0,68$ & 1,00 & $-0,40$ & $-0,12$ & $-0,26$ & $-0,54$ & $-0,67$ & $-0,86$ & $-0,74$ & 0,76 \\
\hline 8 & 0,30 & 0,24 & $-0,34$ & 0,07 & 0,29 & 0,34 & $-0,48$ & 1,00 & 0,19 & 0,30 & 0,44 & 0,42 & 0,25 & 0,05 & $-0,14$ \\
\hline 9 & 0,13 & 0,04 & $-0,00$ & $-0,02$ & 0,18 & 0,19 & $-0,12$ & 0,19 & 1,00 & 0,46 & 0,38 & 0,26 & 0,02 & $-0,02$ & $-0,02$ \\
\hline 10 & 0,40 & $-0,19$ & 0,00 & 0,002 & 0,38 & 0,35 & $-0,26$ & 0,30 & 0,46 & 1,00 & 0,33 & 0,53 & 0,24 & 0,16 & $-0,23$ \\
\hline 11 & 0,41 & 0,09 & $-0,19$ & $-0,15$ & 0,75 & 0,73 & $-0,54$ & 0,44 & 0,38 & 0,33 & 1,00 & 0,52 & 0,33 & 0,23 & $-0,28$ \\
\hline 12 & 0,75 & 0,33 & $-0,33$ & 0,02 & 0,88 & 0,85 & $-0,67$ & 0,42 & 0,26 & 0,53 & 0,52 & 1,00 & 0,54 & 0,39 & $-0,43$ \\
\hline 13 & 0,77 & 0,38 & $-0,32$ & $-0,06$ & 0,49 & 0,54 & $-0,86$ & 0,25 & 0,02 & 0,24 & 0,33 & 0,54 & 1,00 & 0,96 & $-0,97$ \\
\hline 14 & 0,68 & 0,30 & $-0,23$ & $-0,09$ & 0,37 & 0,43 & $-0,74$ & 0,05 & $-0,02$ & 0,16 & 0,23 & 0,39 & 0,96 & 1,00 & $-0,98$ \\
\hline 15 & $-0,69$ & $-0,28$ & 0,24 & 0,10 & $-0,42$ & $-0,47$ & 0,76 & $-0,14$ & $-0,02$ & $-0,23$ & $-0,28$ & $-0,43$ & $-0,97$ & $-0,98$ & 1,00 \\
\hline
\end{tabular}

\section{Construção dos Índices}

Os índices foram calculados a partir da média dos indicadores por bairro. Em seguida, foi feita a padronização dos dados de 0 a 1 , sendo os valores mais próximos a " 0 " os piores resultados e aqueles mais próximos a " 1 " os melhores resultados, os quais são apresentados na Tabela 4. 
Tabela 4 Índices sintéticos para 1991, 2000 e 2010

\begin{tabular}{|c|c|c|c|}
\hline Bairro & Índices 1991 & Índices 2000 & Índices 2010 \\
\hline Abolição & 0,6875 & 0,6957 & 0,6918 \\
\hline Água Santa & 0,7500 & 0,6018 & 0,6744 \\
\hline Benfica & 0,5417 & 0,5865 & 0,3343 \\
\hline Cachambi & 0,8958 & 0,8850 & 0,9408 \\
\hline Cavalcanti & 0,5000 & 0,3372 & 0,5331 \\
\hline Del Castilho & 0,6042 & 0,6027 & 0,5516 \\
\hline Encantado & 0,7917 & 0,7695 & 0,8003 \\
\hline Engenho da Rainha & 0,7083 & 0,6276 & 0,5120 \\
\hline Engenho de Dentro & 0,7500 & 0,6434 & 0,5952 \\
\hline Engenho Novo & 0,6667 & 0,6530 & 0,6970 \\
\hline Freguesia & 0,7917 & 0,6558 & 0,4454 \\
\hline Grajaú & 0,8958 & 0,8752 & 0,7060 \\
\hline Inhaúma & 0,5833 & 0,6008 & 0,3723 \\
\hline Jacaré & 0,6667 & 0,6178 & 0,5656 \\
\hline Jacarepaguá & 0,1458 & 0,0000 & 0,0000 \\
\hline Jacarezinho & - & 0,2772 & 0,1219 \\
\hline Lins de Vasconcelos & 0,6250 & 0,5491 & 0,3044 \\
\hline Mangueira & 0,0000 & 0,3205 & 0,0570 \\
\hline Maracanã & 1,0000 & 1,0000 & 0,9643 \\
\hline Maria da Graça & 0,7292 & 0,7564 & 0,3681 \\
\hline Méier & 0,8958 & 0,9595 & 1,0000 \\
\hline Piedade & 0,7292 & 0,7183 & 0,7198 \\
\hline Pilares & 0,6875 & 0,7002 & 0,7604 \\
\hline Quintino & 0,7292 & 0,6736 & 0,6638 \\
\hline Riachuelo & 0,7500 & 0,7285 & 0,6898 \\
\hline Rocha & 0,7708 & 0,7701 & 0,7187 \\
\hline Sampaio & 0,3958 & 0,4041 & 0,3933 \\
\hline São Francisco Xavier & 0,7500 & 0,7166 & 0,5852 \\
\hline Todos os Santos & 0,8125 & 0,7947 & 0,7732 \\
\hline Tomás Coelho & 0,6458 & 0.4008 & 0,3588 \\
\hline Vila Isabel & 0,8750 & 0,7939 & 0,6957 \\
\hline
\end{tabular}


Para 0 ano de 1991, o pior índice corresponde ao bairro da Mangueira e 0 maior índice ao bairro do Maracanã, destacados em negrito. Ressalta-se que nenhum dos bairros em destaque são constituintes da RA do Méier. Todavia, considerando apenas os bairros da RA XIII, o melhor resultado é do bairro do Méier e o pior é do bairro de Sampaio.

Para 0 ano de 2000, o pior resultado corresponde ao bairro de Jacarepaguá, destacado em negrito, seguido do bairro do Jacarezinho e Mangueira, que apresentam valores bem próximos, e 0 melhor resultado corresponde ao bairro do Maracanã, destacado em negrito.

Para 0 ano de 2010, o pior resultado continua sendo pertencente ao bairro de Jacarepaguá, destacado em negrito, porém, daqueles pertencentes à RA do Méier, 0 bairro com o pior resultado é 0 Lins de Vasconcelos, e o melhor resultado corresponde ao bairro do Méier, destacado em negrito.

Ao se comparar os bairros nos diferentes anos de pesquisa censitária, nota-se que as melhores posições são sempre revezadas por Méier e Maracanã, seguidos dos bairros de Cachambi e Grajaú. Com isso, verifica-se o forte destaque da RA do Méier perante as demais regiões administrativas da cidade, já que seus índices estão muito próximos aos de outros bairros importantes para a cidade como Grajaú e Maracanã, o que pode ser explicado pela correlação espacial, denotando aspectos de vizinhança que são capazes que prover grande influência nos bairros da RA do Méier.

Com relação às piores posições, destaca-se a recorrência do bairro de Jacarepaguá no ranking, tendo em vista o bairro apresentar nas décadas anteriores grandes vazios demográficos, o que influencia diretamente na resposta dos indicadores, isto é, em comparação com os demais bairros, a baixa concentração populacional, em termos proporcionais, colocam os indicadores em desvantagem. Já a Mangueira e 0 Jacarezinho se posicionam nos piores lugares por serem caracterizados como bairros com forte concentração de aglomerados subnormais, ou seja, nessas regiões os indicadores fornecem as piores respostas.

0 bairro do Rocha é um dos que mais chama a atenção, tendo em vista não ser um bairro muito conhecido, mas mesmo assim apresenta resultados relativamente bons para todos os anos, caracterizando 0 seu aspecto de estagnação. Já os bairros de Piedade e Pilares tiveram grandes melhorias, haja vista sua crescente evolução ao longo dos anos. Isto pode ser explicado pelos investimentos que os bairros vêm recebendo com a construção de grandes condomínios e elementos de infraestrutura e serviços em suas áreas territoriais e em bairros vizinhos, como o Cachambi, que está sempre na ponta do ranking com os melhores indicadores. Outros bairros que recebem forte influência de seus vizinhos é o de Encantado, vizinho do bairro de Cachambi, e Todos os Santos, vizinho do bairro do Méier, sendo considerado, inclusive como pertencente ao Grande Méier. 
0 bairro do Méier, por ser um bairro central, recebeu grandes incentivos de crescimento urbano, e, por isso, desponta nas primeiras posições, apontando os meIhores índices. Contudo há de se notar que ao se comparar os demais bairros da Região Administrativa do Méier, observa-se, em termos gerais, uma piora nos índices de 1991 a 2010. Isto demonstra as desigualdades dos investimentos para cada bairro, pois nesse período denota-se apenas o crescimento de bairros como 0 Méier, já citado anteriormente, e Cachambi.

0 bairro do Engenho de Dentro teve uma piora nos índices, ao se comparar os anos de 1991 e 2000, porém para 0 ano de 2010, observa-se a tentativa de erguimento da melhoria da qualidade de vida. Isto vem sendo impulsionado pelo incentivo à cultura, através da implantação de um estádio olímpico ("Engenhão") e da melhoria em sua infraestrutura de vias, com a construção do viaduto da Abolição, da estrutura de canais, reduzindo a ocorrência de enchentes na região, além do crescimento de moradias ao redor do "Engenhão".

Nos mapas da Figura 5 verifica-se a espacialização desses índices, propiciando maiores facilidades na identificação dessas alterações, atento as percepções de vizinhança, que provavelmente influenciam na resposta dos indicadores.

Ao analisar a distribuição dos índices, comprova-se a forte segregação que ocorre nessa região e em bairros vizinhos, pois ao se avaliar, por exemplo, 0 bairro do Maracanã e 0 bairro da Mangueira, nota-se que apesar de serem vizinhos, àquele apresenta sempre os melhores resultados e este os piores. Sendo assim, a segregação se impõe como uma barreira social formando "mundos" completamente distantes, mesmo com a proximidade territorial. Com isso, constata-se que mesmo com a ideia da vizinhança influenciar um requerido bairro, há exceções quando ocorre 0 efeito da segregação urbana, principalmente em regiões que apresentam aglomerados subnormais.

Os bairros de Piedade e Abolição permaneceram na mesma classe, já Encantado e Pilares tiveram melhorias em seus resultados, principalmente ao se observar as variáveis de moradores por domicílio e da proporção de dependentes que apresentaram uma ligeira queda em seus valores proporcionais.

\section{Análise da correlação espacial dos índices encontrados}

$\mathrm{Na}$ análise da correlação espacial, foi empregada a estatística de Moran com o Índices global e local de Moran. 0 índice de Moran global fornece um único valor como medida da associação espacial para todo o conjunto de dados de uma área, sendo de grande utilidade para a caracterização de toda a região de estudo. 0 Índice de Moran local permite examinar padrões, em uma escala de maior detalhe, de modo a identificar a existência de áreas de clusters e outliers. Tanto 0 índice local como 
Figura 5 Índices sintéticos para os anos de 1991, 2000 e 2010

1991

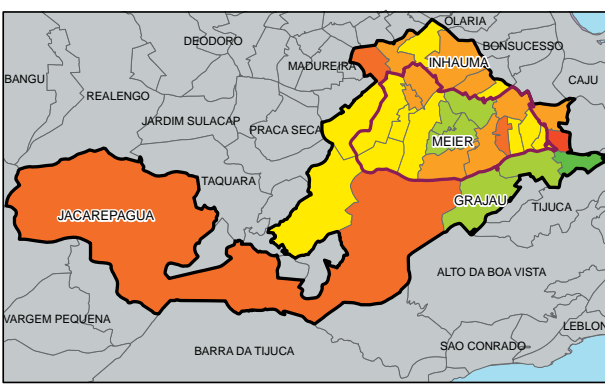

2010

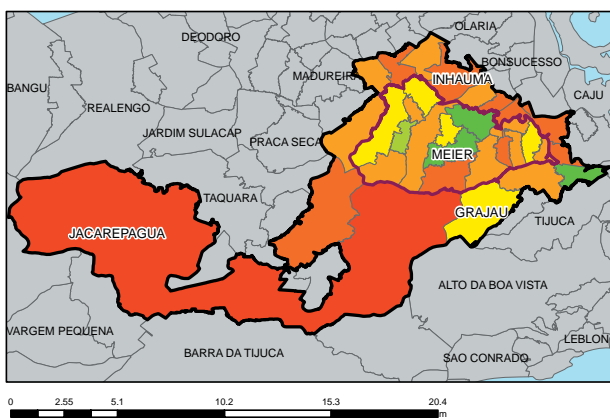

2000
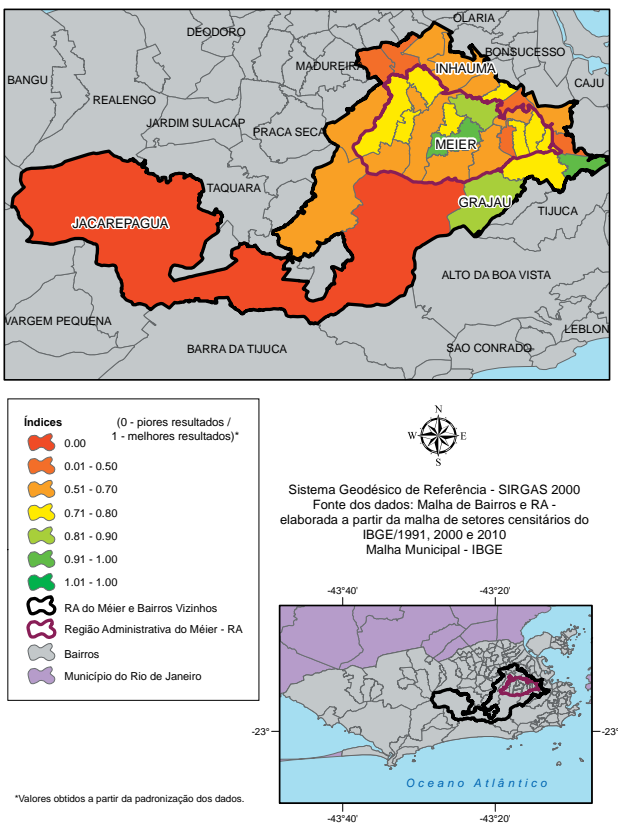

global de Moran fornece um valor específico de correlação, considerando seu arranjo espacial através de uma matriz que descreve as vizinhanças das áreas. A diferença é que 0 índice local é calculado para cada área da região de estudo e 0 global para toda área representativa da região de estudo.

Na estatística de Moran, a hipótese nula é de independência espacial, que nesse caso, o valor do índice de Moran assume zero, em caso de valores positivos (entre $0 \mathrm{e}+1$ ) indicam uma correlação direta e caso contrário, valores negativos (entre $0 \mathrm{e}-1$ ) indicam uma correlação inversa.

Uma vez calculado o índice de Moran, é importante estabelecer sua validade estatística. Para isso é aplicado um teste de significância no qual são geradas diferentes permutações dos valores de atributos associados às regiões; cada permutação produz um novo arranjo espacial. Neste trabalho, foi utilizado o nível de significância de 5\% e 99 permutações, ou seja, serão áreas com autocorrelação espacial estatisticamente significativa quando 0 valor-p for menor ou igual a 0,05 . 0 s valores do Índice de Moran global e o seu respectivo $p$-valor para o índice sintético para cada ano estudado estão descritos na Tabela 5. 
Tabela 5 Valores do Índice de Moran calculados e sua significância

\begin{tabular}{|ccc|}
\hline Ano & Índice Global de Moran & Significância \\
\hline 1991 & $-0,0964$ & 0,09 \\
2000 & $-0,0345$ & 0,34 \\
2010 & 0,0463 & 0,29 \\
\hline
\end{tabular}

Verifica-se que para os anos de 1991, 2000 e 2010 não há autocorrelação espacial do índice calculado, uma vez que 0 índice de Moran teve significância de 0,09, 0,34 e 0,29. Um índice de valor pequeno, juntamente com a significância acima de 0,05 , traz evidências de que não se deve rejeitar a hipótese de que não há autocorrelação espacial. Isto é comprovado ao se observar a Figura 5, na qual o mapa mostra que não há um padrão claramente observado.

Ao se calcular o índice, percebe-se que mesmo analisando numa escala de maior detalhe os índices não são significantes nos três anos analisados, haja vista que apenas 0 bairro de Todos os Santos está com 0 valor índice local de Moran de 0,534 e significância inferior a 0,05. Para 0 ano de 2010 constata-se ainda que 0 bairro de Benfica se enquadra também nesta situação. 0s demais bairros apresentam valores de significância para as correlações locais bem maiores, chegando até em 0,59 para o bairro de Inhaúma no ano 2000 (Tabela 6).

Tabela 6 Índices de Moran local e significância dos índices

(continua)

\begin{tabular}{|lcccccc|}
\hline & \multicolumn{2}{c}{1990} & \multicolumn{2}{c}{2000} & & 2010 \\
\cline { 2 - 4 } & $\begin{array}{c}\text { Índ. Moran } \\
\text { Local }\end{array}$ & Significância & $\begin{array}{c}\text { Índ.Moran } \\
\text { Local }\end{array}$ & $\begin{array}{c}\text { Significância } \\
\text { Abolição }\end{array}$ & $\begin{array}{c}\text { Índ. Moran } \\
\text { Local }\end{array}$ & Significância \\
\hline Água Santa & 0,012 & 0,37 & 0,0998 & 0,33 & 0,3161 & 0,07 \\
\hline Benfica & $-0,0387$ & 0,41 & 0,0625 & 0,12 & $-0,0995$ & 0,30 \\
\hline Cachambi & 0,4337 & 0,10 & 0,1322 & 0,08 & 0,7718 & 0,00 \\
\hline Cavalcanti & 0,2122 & 0,23 & 0,1569 & 0,35 & 0,1037 & 0,42 \\
\hline Del Castilho & $-0,0949$ & 0,48 & 0,2666 & 0,35 & $-0,0077$ & 0,35 \\
\hline Encantado & $-0,1018$ & 0,41 & $-0,066$ & 0,21 & $-0,0004$ & 0,52 \\
\hline Engenho da Rainha & 0,1341 & 0,31 & 0,0894 & 0,43 & 0,4019 & 0,26 \\
\hline
\end{tabular}


Tabela 6 Índices de Moran local e significância dos índices

(conclusão)

\begin{tabular}{|c|c|c|c|c|c|c|}
\hline \multirow[b]{2}{*}{ BAIRRO } & \multicolumn{2}{|c|}{1990} & \multicolumn{2}{|c|}{2000} & \multicolumn{2}{|c|}{2010} \\
\hline & $\begin{array}{l}\text { Índ. Moran } \\
\text { Local }\end{array}$ & Significância & $\begin{array}{l}\text { Índ.Moran } \\
\text { Local }\end{array}$ & Significância & $\begin{array}{l}\text { Índ. Moran } \\
\text { Local }\end{array}$ & Significância \\
\hline Engenho de Dentro & 0,0141 & 0,47 & 0,0026 & 0,46 & 0,0264 & 0,13 \\
\hline Engenho Novo & $-0,0139$ & 0,34 & 0,0356 & 0,19 & 0,1968 & 0,16 \\
\hline Freguesia & $-0,2431$ & 0,20 & $-0,0634$ & 0,08 & 0,109 & 0,29 \\
\hline Grajaú & $-0,5219$ & 0,23 & $-0,7617$ & 0,08 & $-0,3333$ & 0,11 \\
\hline Inhaúma & $-0,1261$ & 0,30 & $-0,0061$ & 0,59 & $-0,1222$ & 0,31 \\
\hline Jacaré & 0,0002 & 0,46 & 0,0069 & 0,38 & $-0,0008$ & 0,36 \\
\hline Jacarepaguá & $-1,0596$ & 0,19 & $-0,4296$ & 0,48 & 0,2146 & 0,35 \\
\hline Jacarezinho & - & - & $-0,7271$ & 0,24 & 0,1345 & 0,44 \\
\hline Lins de Vasconcelos & 0,0108 & 0,49 & 0,0198 & 0,37 & $-0,1419$ & 0,51 \\
\hline Mangueira & $-1,3718$ & 0,21 & $-0,9661$ & 0,14 & $-0,5181$ & 0,36 \\
\hline Maracanã & $-1,0517$ & 0,09 & $-0,2171$ & 0,36 & $-0,8109$ & 0,22 \\
\hline Maria da Graça & 0,0513 & 0,48 & $-0,1334$ & 0,30 & 0,0988 & 0,32 \\
\hline Méier & 0,3659 & 0,15 & 0,5193 & 0,20 & 0,6874 & 0,19 \\
\hline Piedade & 0,0224 & 0,42 & $-0,0606$ & 0,30 & 0,124 & 0,18 \\
\hline Pilares & 0,001 & 0,45 & $-0,0321$ & 0,34 & $-0,084$ & 0,37 \\
\hline Quintino & 0,0161 & 0,52 & $-0,0573$ & 0,26 & $-0,0024$ & 0,45 \\
\hline Riachuelo & $-0,0035$ & 0,41 & 0,0226 & 0,49 & 0,053 & 0,39 \\
\hline Rocha & 0,082 & 0,26 & $-0,0495$ & 0,44 & $-0,1748$ & 0,35 \\
\hline Sampaio & $-0,4081$ & 0,35 & $-0,3359$ & 0,31 & $-0,2768$ & 0,24 \\
\hline São Francisco Xavier & $-0,0704$ & 0,37 & 0,1091 & 0,26 & $-0,004$ & 0,5 \\
\hline Todos os Santos & 0,5342 & 0,01 & 0,7134 & 0,03 & 0,9602 & 0,01 \\
\hline Tomás Coelho & 0,0182 & 0,35 & 0,2196 & 0,26 & 0,2239 & 0,35 \\
\hline Vila Isabel & 0,3168 & 0,1 & 0,3648 & 0,11 & 0,2405 & 0,12 \\
\hline
\end{tabular}

\section{Construção dos mapas temáticos}

Para verificar a ocorrência de desigualdades sociais na Região Administrativa do Méier, buscou-se construir mapas que apresentassem a espacialização do diagrama de espalhamento de Moran. Este diagrama é uma forma adicional de se visualizar a dependência espacial, facilitando assim 0 entendimento do "efeito vizinhança”, de modo a colocar os índices de cada bairro em comparação com aqueles ditos adjacentes. 
Figura 6 Diagrama de Espalhamento de Moran

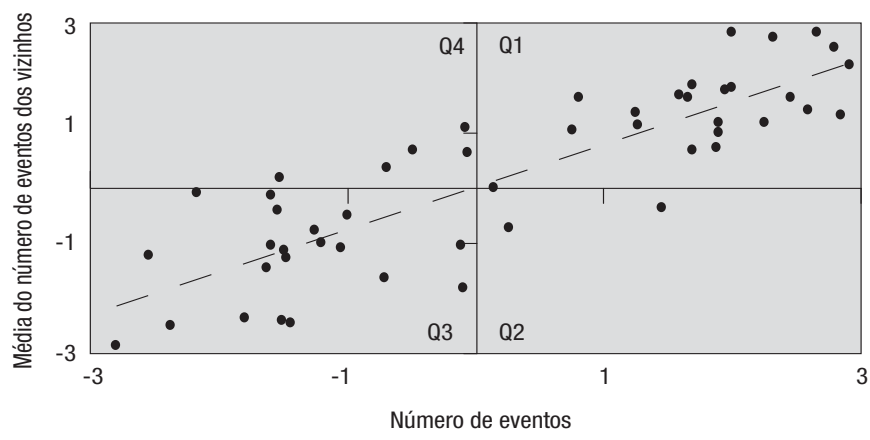

Fonte: Druck et al. (2004).

0 diagrama de espalhamento, segundo Marques et al. (2010), possibilita visualizar e interpretar a associação linear entre cada valor de atributo em relação à média dos valores dos atributos de seus vizinhos. A origem do gráfico de espalhamento está centrada na coordenada $(0,0)$, sendo dividido em quatro quadrantes, de maneira que cada quadrante representa um tipo diferente de associação entre 0 valor de uma dada área e a média de seus vizinhos. Os quadrantes podem ser interpretados como:

1. Q1 (valores positivos, médias positivas) e Q2 (valores negativos, médias negativas): indicam pontos de associação espacial positiva, no sentido que uma localização possui vizinhos com valores semelhantes; e

2. Q3 (valores positivos, médias negativas) e Q4 (valores negativos, médias positivas): indicam pontos de associação espacial negativa, no sentido que uma localização possui vizinhos com valores distintos.

\section{Análise dos resultados}

No que tange ao comparativo dos dados estudados ao longo dos anos, conforme apresentado na Figura 5, presume-se, de acordo com as informações adquiridas com a interpretação dos mapas, gráficos e tabelas, que a piora dos indicadores, em relação aos anos anteriores, pode ser explicada pelos intensos e constantes investimentos nas regiões administrativas da zona sul da cidade. Além disso, nota-se melhorias somente em alguns bairros da RA do Méier, os demais ficaram esquecidos ao longo desses anos, sendo caracterizados apenas como bairros residenciais, serventes aos centrais que são Méier e Cachambi.

0 bairro de Jacarepaguá, em todos os anos, se enquadrou como o bairro com os menores índices. Entre outras razões, pode ter sido determinado pela barreira 
Figura 7 Visualização da Serra dos Pretos-Forros (Jacarepaguá-Grajaú)

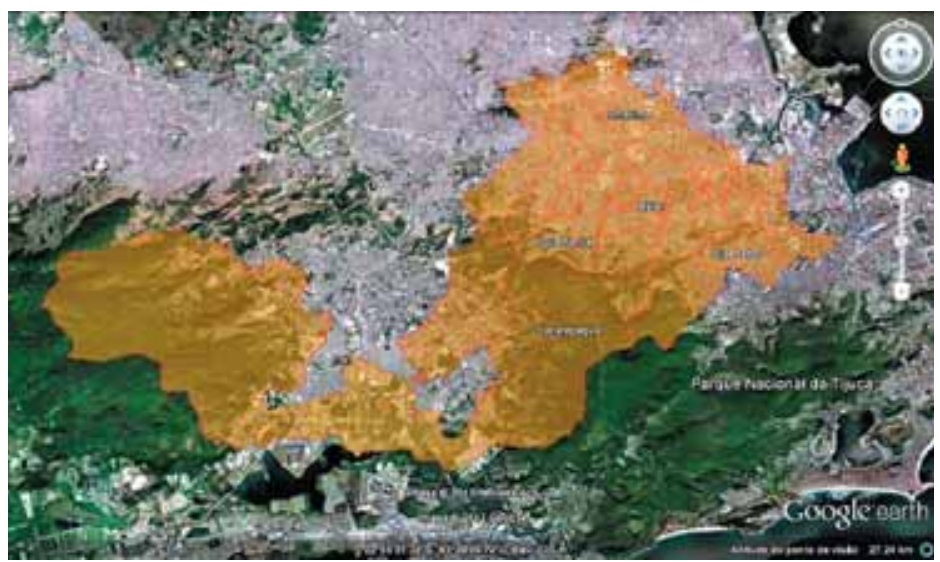

física que existe por causa da presença da Serra dos Pretos-Forros (Figura 7). Para os demais anos, este efeito foi minimizado com a construção da Linha Amarela, contudo os resultados mantiveram-se ruins. 0 bairro de Jacarepaguá entra como uma área ainda isolada e distante, não permitindo uma fluência significativa das melhorias implantadas nos seus bairros vizinhos. Dessa forma, o peso do índice deste bairro afeta, consideravelmente, bairros adjacentes, como: Lins de Vasconcelos e Água Santa.

Analisando a espacialização do diagrama de espalhamento de Moran para os anos de 1991, 2000 e 2010, observa-se que para 0 ano de 1991 (Figura 8 - 1991), a RA do Méier apresenta um padrão quase homogêneo em sua classificação. Praticamente todos os bairros dessa Região Administrativa estão contidos no primeiro quadrante, isto é, eles apresentam altos índices e seus vizinhos também. Contudo, os bairros Lins de Vasconcelos e Jacaré apresentam o inverso, ou seja, índices baixos e vizinhos com índices baixos. Sendo assim, no que tange aos aspectos de segregação espacial, nota-se, por este mapa e pelo mapa dos índices-síntese (Figura 5), que há desigualdades socioespaciais nesta região, haja vista algumas áreas serem mais favorecidas que outras. Para 0 ano de 2000 (Figura 8 - 2000), nota-se um aumento na classificação dos bairros pertencentes ao segundo quadrante, isto se explica, pois alguns bairros tiveram pioras em seus índices, juntamente com seus vizinhos. Para 0 ano de 2010 (Figura 8 - 2010), o maior número de bairros encontra-se no quarto quadrante, pois este censo foi o que registrou os piores índices para a maioria dos bairros.

Comparando os dados apresentados, juntamente com as interpretações dos mapas confeccionados, conclui-se que o bairro do Méier ainda é considerado o bairro central desta Região Administrativa, e por isso, é o que ainda apresenta os melhores 
Figura 8 Espacialização do diagrama de espalhamento de Moran para os anos de 1991, 2000 e 2010
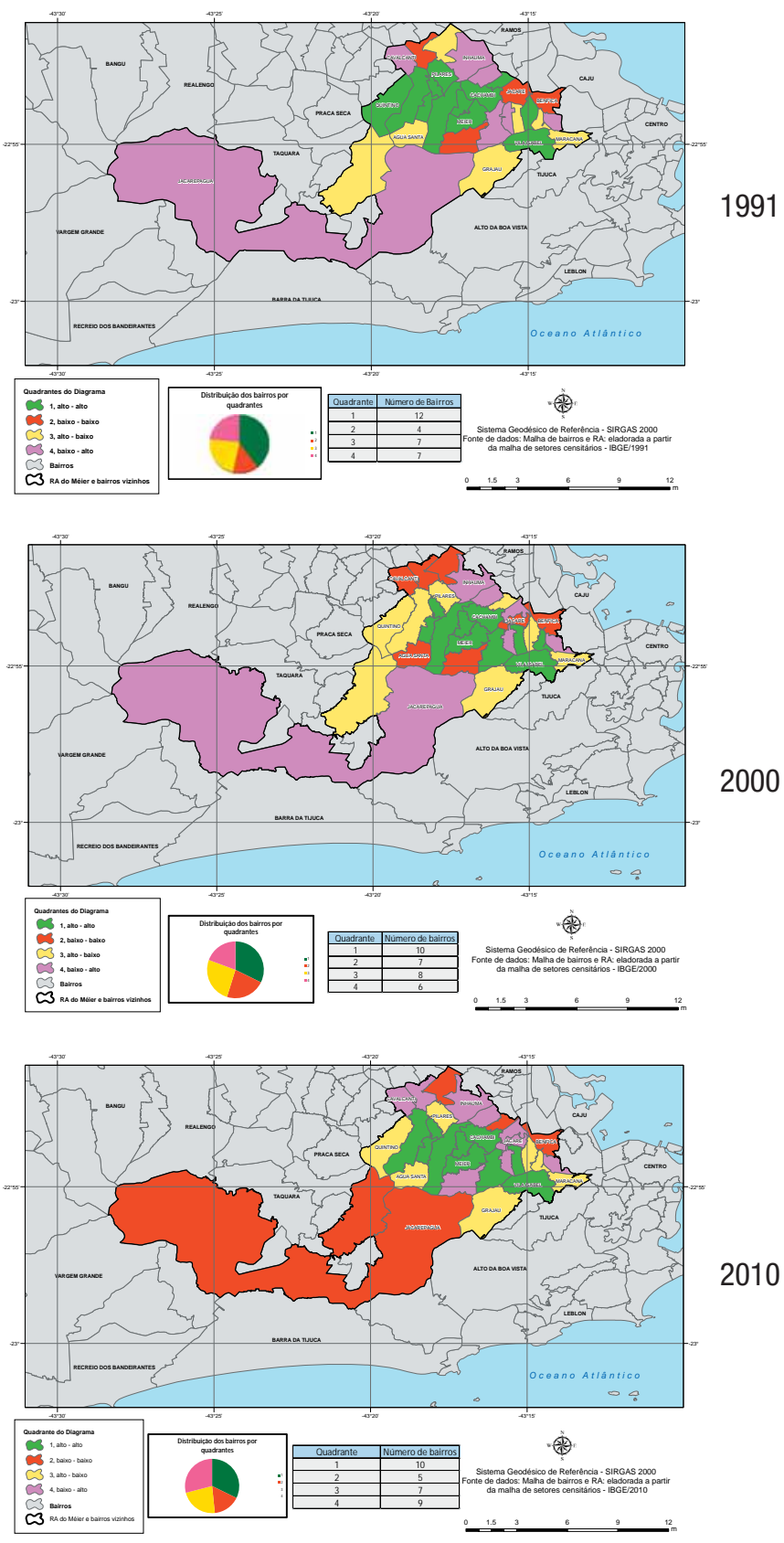
resultados dos indicadores. A sua presença nesta região fornece, ainda, uma grande dependência espacial por seus bairros vizinhos, fato comprovado ao se observar os mapas da Figura 8 - 1991, 2000 e 2010. Entretanto, tendo em vista a promoção de novos bairros centrais para a região, destaca-se a grande importância do bairro do Cachambi, vizinho ao bairro do Méier. Ele recebeu investimentos com a criação de um shopping que garantiu a revitalização da área e criou um ambiente favorável para 0 crescimento imobiliário da região e para a implantação de novos negócios. Entretanto, os demais bairros da RA têm seus índices bem próximos, sendo assim, perceptível a diferença de investimentos nos bairros da região.

Dentre os bairros estudados, elencaram-se aqueles que apresentaram melhorias, e aqueles que passaram por algum retrocesso em seus índices e foi construído o mapa da Figura 9. Ao observá-lo, nota-se que a maior parte dos bairros não obteve melhorias ao longo dos anos, contudo, ressalta-se que apesar de alguns estarem classificados como aqueles bairros que não tiveram grandes alterações de melhorias, há algumas diferenças não muito significativas.

Dessa forma, percebe-se que durante muito tempo a região ficou esquecida pelos provedores de melhorias, que tem como principal agente modelador, 0 estado, replicando assim, o mesmo cenário do início da pesquisa, com o bairro do Méier sendo o responsável pela centralidade urbana, mas com o crescimento de alguns de seus vizinhos, a citar, o Cachambi.

Figura 9 Bairros que melhoraram, pioraram ou permaneceram sem grandes mudanças nos anos estudados

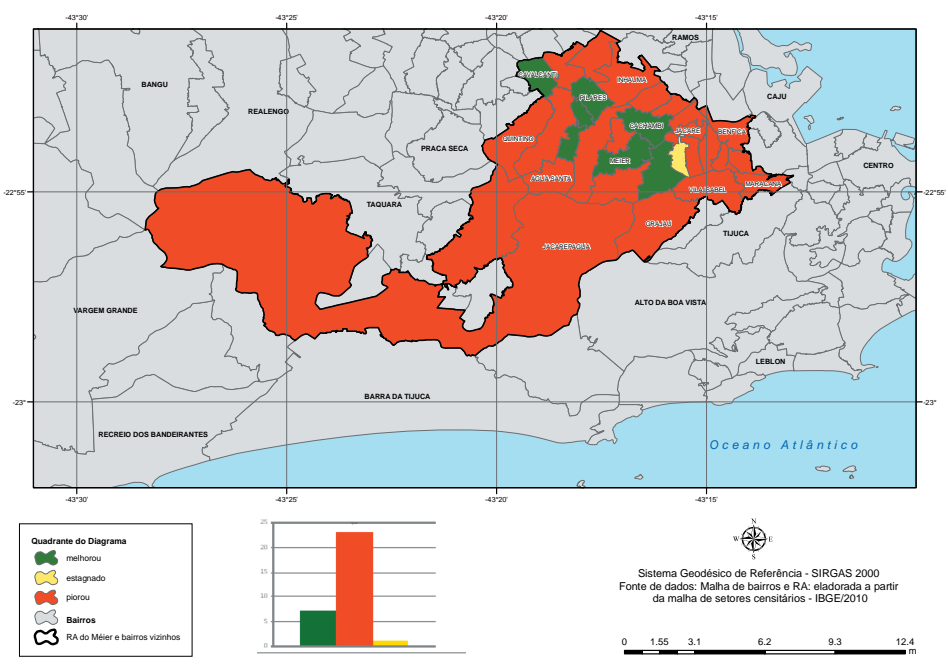




\section{Considerações Finais}

A metodologia utilizada propiciou a identificação de distintos padrões de desigualdade socioeconômica presentes na Região Administrativa do Méier, nos anos de 1991, 2000 e 2010. Todavia, ressalta-se que a técnica utilizada neste trabalho para a construção do índice foi a média, contudo poderiam ser utilizadas outras técnicas, como, por exemplo, a análise multivariada.

Entende-se que subjacente a tais padrões de desigualdade identificados pela metodologia apresentada opera um processo de segregação socioespacial decorrente da dinâmica territorial em curso na região, em especial com as transformações ocorridas na última década.

A pesquisa revelou um quadro de distribuição espacial das desigualdades socioeconômicas segundo 0 qual as melhores condições de vida se localizavam na parte central da RA, a citar Méier e Cachambi, fazendo com que se comprovasse a hipótese principal deste trabalho, segundo a qual seria possível notar uma sensível diferenciação entre as condições socioeconômicas dos ditos bairros centrais em relação aos periféricos.

Ressalta-se a abertura da Linha Amarela como vetor dominante no processo de reconfiguração do território na Região Administrativa do Méier. A implementação desse eixo viário viabilizou a redefinição de estratégias dos agentes modeladores do uso do solo urbano. Os impactos mais significativos advindos desse vetor espacial podem ser visualizados no dinamismo do mercado imobiliário e na sofisticação da pauta de bens e serviços oferecidos à população.

A análise da ação conjunta dos agentes modeladores do espaço urbano se mostra essencial para a compreensão dos processos de segregação urbana, sobretudo em relação à importância das ações do estado. Sendo este 0 agente responsável pela dotação de infraestrutura urbana, uma provável explicação para o padrão espacial encontrado pode estar associada à seletividade espacial na implementação das políticas públicas. Assim, é fundamental avaliar o comportamento de indicadores sociais para identificar e também as possíveis medidas para implementar melhorias na região.

A análise de áreas demostrou ser um importante processo dentro da ferramenta do geoprocessamento para estudos deste tipo. Através dela foi possível verificar a existência de algum padrão espacial nos valores observados, do que são exemplos os efeitos de heterogeneidade e autocorrelação espacial.

Embora 0 índice de Moran Global calculado para cada ano estudado tenha sido muito baixo e não tenha apresentado significância com base nos $95 \%$ do nível de confiança, o índice de Moran Local já apresentou valores maiores, ou seja, com ele se torna possível evidenciar as áreas que possuem maiores semelhanças, 
e, portanto, geram agrupamentos. Além disso, uma maneira adicional de visualizar a dependência espacial é com 0 uso do diagrama de espalhamento de Moran que, no âmbito deste trabalho, foi representado em um mapa coroplético, onde cada classe de cor representa um quadrante do diagrama. Com isso foi possível notar na prática as melhorias, estagnações e pioras de cada bairro.

Por fim, a partir da constatação de que 0 espaço é dinâmico e está em constante transformação, faz-se necessário governar através das diferenças, ou seja, levando-se em consideração as particularidades de cada região. Por isso, conhecer essas diferenças é fundamental para atuar na redução de assimetrias socioespaciais.

Assim sendo, 0 intuito deste trabalho foi contribuir com a discussão sobre 0 tema pesquisado. Outras hipóteses poderão surgir fazendo com que este estudo esteja longe de se esgotar. Pretendeu-se aqui iluminar algumas questões que possam embasar futuras discussões e intervenções no âmbito do planejamento urbano. 


\section{Referências}

ADEMI - Associação dos Dirigentes de Empresas do Mercado Imobiliário.

Disponível em: http://www.ademi.org.br/. Acesso: 16 mai. 2012.

CAUM0, Rafael Bassegio. Estatística Espacial em Dados de Área: Uma Modelagem Inteiramente Bayesiana para o mapeamento de Doenças Aplicada à Dados

Relacionados com a Natalidade em Mulheres Jovens de Porto Alegre. Universidade Federal do Rio Grande do Sul. Instituto de Matemática. Departamento de Estatística, 2006.

DRUCK, S.; CARVALHO, M.S.; CÂMARA, G.; MONTEIRO, A.V.M. Análise Espacial de Dados Geográficos. Brasília, EMBRAPA, 2004 (ISBN: 85-7383-260-6).

INSTITUTO BRASILEIRO DE GEOGRAFIA E ESTATÍSTICA (IBGE). Disponível em: http://www.ibge.gov.br/home/. Acesso: 02 mar. 2012.

INSTITUTO BRASILEIRO DE GEOGRAFIA E ESTATÍSTICA (IBGE). Apresentação Aglomerados Subnormais no Censo Demográfico 2010. Rio de Janeiro, 15 dez. 2011. Disponível em: http://www.ibge.gov.br/home/presidencia/noticias/imprensa/ ppts/. Acesso 01 dezembro 2012.

INSTITUTO BRASILEIRO DE GEOGRAFIA E ESTATÍSTICA (IBGE). Indicadores de Desenvolvimento Sustentável. IBGE. 2004. Disponível em: http://www.ibge.gov.br. Acesso em: 05 mai. 2012.

INSTITUTO BRASILEIRO DE GEOGRAFIA E ESTATÍSTICA (IBGE). Indicadores básicos de saúde no Brasil: conceitos e aplicações. Rede Interagencial de Informações para a Saúde (RIPSA) Brasília: Organização Pan-Americana da Saúde, 2002. 299 p. : il.

INSTITUTO PEREIRA PASSOS (IPP). Armazém de Dados / Bairros Cariocas. Rio de Janeiro, 2010. Disponível em: http://portalgeo.rio.rj.gov.br/bairroscariocas. Acesso em: 25 julho 2012.

KLEIMAN, Mauro. A Via Expressa "Linha Amarela" e seus impactos no território da metrópole do Rio de Janeiro. Chão Urbano, ano X, n. 6, nov. - dez., 2010.

KREMPI, Ana Paula. Explorando recursos de estatística espacial para análise da acessibilidade na cidade de Bauru. 2004. Dissertação (Mestrado) - Universidade de São Paulo, Escola de Engenharia de São Carlos, São Carlos.

MARQUES, A. P. S.; HOLZSCHUH, M. L.; TACHIBANA, V. M.; NOBUHIRO, N. I. Análise Exploratória de Dados de Área para Índices de Furto na Mesorregião de Presidente Prudente - SP. In: III Simpósio Brasileiro de Ciências Geodésicas e Tecnologias da Geoinformação, Recife - PE, p. 001 - 008, 27-30 de Julho de 2010.

MARTINS, Paulo Cesar. Desigualdades socioespaciais no Município do rio de janeiro: um foco na Região Administrativa de vigário geral. ENCE / IBGE, 2011.

NAÇÕES UNIDAS. Handbook of vital statistics methods. Studies in Methods, Série F, n. 7. New York: Nações Unidas, 1955. 
NAÇÕES UNIDAS. Methodology and evaluation of population registers and similar systems. Studies in Methods, Série F, n.15. New York: United Nations Statistical Office, 1969.

NAÇÕES UNIDAS. Principles and Recommendations for Population and Housing Censues. Statistical Papers, Série M, n. 67, Rev. 2. New York: Nações Unidas, 2008.

PNUD - Programa das Nações Unidas para o Desenvolvimento. Valores e Desenvolvimento Humano 2010. Relatório de Desenvolvimento Humano Brasileiro 2009/2010. Brasília, 2010.

PRUDENTE, V. H. R.; PRADO, M. L. do; MERCANTE, E.; OPAZO, M. A. U. Análise Espacial da evolução das áreas municipais plantadas com soja no estado do Paraná, durante as safras de 2003/2004 a 2007/2008. In Simpósio de Inovação Tecnológica - SITEC. Cascavel, 31/08, 01 e 02/09/2011.

RIGOTTI, José Irineu Rangel. A Análise Exploratória de Dados Espaciais: breve introdução. Disponível em: http://www.observatoriodasmetropoles.ufrj.br/ apresentacoes/6_analise_exploratoria.pdf. (2005) Acesso: 01 set. 2012.

SEBRAE - Serviço Brasileiro de Apoio às Micro e Pequenas Empresas. Informações Socioeconômicas da Região Administrativa do Méier. Rio de Janeiro, 2011.

SIDRA: Sistema IBGE de Recuperação Automática. Disponível em: http://www. sidra.ibge.gov.br/.

VALENTE, K.; STRAUCH, J. C. M.; FERNANDES, F. R. C. \& JIMENEZ, R. C.. Análise de mapas temáticos para representar indicadores de desenvolvimento em Município com atividades de extração mineral: Estudo de caso em Paracatu (MG). In: XXV Congresso Brasileiro de Cartografia, 2011, Curitiba.

VILLAÇA, Flávio. Espaço intra-urbano no Brasil. São Paulo: Studio Nobel, 1998. 